\title{
PHYSIOLOGICAL ASPECTS OF THE HEATING AND VENTILATION OF HOUSES IN BRITAIN
}

\begin{abstract}
$\mathrm{A}^{\mathrm{T}}$
$T$ the recent meeting in Oxford of the British Association, the first session of Section I (Physiology), held on September 2, dealt with various physiological aspects of heating and ventilation, the emphasis of the papers being on the requirements of houses in Great Britain.

In his introduction the chairmen, Dr. Thomas Bedford, gave a brief survey of the results of recent studies of thermal comfort and the assessment of environmental warmth. It can be concluded from recent research in the United States that for satisfactory ventilation the supply of fresh air should be at the rate of not less than $600 \mathrm{cu}$. $\mathrm{ft}$. $/ \mathrm{hr}$. for each person, and this standard had been accepted by the Egerton Committee as one of the requirements for post-war housing. People doing light work during the winter months in Great Britain liked a temperature of about $65^{\circ} \mathrm{F}$. and were reasonably comfortable at temperatures of between 60 and $68^{\circ} \mathrm{F}$. With a suitable temperature there should be adequate but not excessive air movement. At room temperatures of about $65^{\circ} \mathrm{F}$. the air speed should be between 20 and $40 \mathrm{ft} . / \mathrm{min}$. At lower speeds complaints of stuffiness are likely, and at higher speeds sensitive persons will complain of draughts.
\end{abstract}

Investigations have confirmed that with a given level of warmth most people find conditions pleasanter when the boundary surfaces of a room are warmer than the air than when they are cooler. It is undesirable that the warmth around the head should be appreciably greater than that near the floor. The gradient of air temperature over the height of a man should not be more than $5^{\circ} \mathrm{F}$. When a room is heated by panels embedded in the ceiling, the elevation of the mean radiant temperature at head-level due to the warm ceiling should not exceed $4^{\circ} \mathrm{F}$. Many buildings are now warmed by heating the floors. Research nearly completed shows that for sedentary people the temperature of the floor surface should not be higher than $75^{\circ} \mathrm{F}$.; but people who are moving about can tolerate a rather higher temperature. These figures relate to rooms with an air temperature of about $65^{\circ} \mathrm{F}$.

Various scales of warmth have been used for making allowance for different combinations of the individual factors which make up the thermal environment. The best known of these is the American scale of effective temperature. This makes no specific allowance for radiant heat, and during the Second World War it became necessary to attempt some adjustment of the scale to allow for radiation effects. Such an adjustment has been made by using the temperature of a black-globe thermometer instead of the air temperature in calculating the effective temperature. Recent physiological research carried out at the R. N. Tropical Research Unit, Singapore, has shown that this method of adjustment gives good results.

War-time studies have led to certain criticisms of effective temperature as an index of the stress imposed by work in hot environments, but a recent study of the bases of these criticisms has led to the conclusion that effective temperature, properly used, remains a valuable index of warmth. Finally, it was suggested by Dr. Bedford that attention should be given to local methods of warming a person rather than the whole room or the whole house, especially with reference to the requirements of the aged. Dr. E. F. DuBois had asked: "Why overheat 100 tons of house and furniture, when all that is necessary is to warm $100 \mathrm{lb}$. of grandmother?"

Prof. G. P. Crowden spoke on the heating and ventilation requirements of dwellings. $\mathrm{He}$ outlined the climatic factors which affect the control of body temperature and the comfort of the individual, and then detailed the standards set out in the codes of practice drawn up by the British Standards Institution. In living-rooms the temperature should lie between 60 and $68^{\circ} \mathrm{F}$. and in bedrooms between 55 and $57^{\circ} \mathrm{F}$. In both, the relative humidity should be between 30 and 65 per cent, with a fresh air supply of $600 \mathrm{cu} . \mathrm{ft} . / \mathrm{hr}$. per person. For kitchens a tempera ture of $60^{\circ} \mathrm{F}$. is specified, with a relative humidity of less than 70 per cent, and the supply of fresh air should be at least $2,000 \mathrm{cu}$. ft. $/ \mathrm{hr}$.

Prof. Crowden then went on to describe tests that had been carried out in experimental rooms of the type described as 'kitchen/living-room', with housewives and men of varying ages as the experimental subjects. These tests showed that the provisions for heating and ventilation make it possible to maintain the specified conditions.

When housing schemes were again undertaken after the Second World War, it was evident that building resources would be stretched to the utmost, and methods of economy in building were examined. One obvious way of saving in both cost and materials was to reduce the heights of rooms. Generally it was not permissible to build houses with rooms less than $8 \mathrm{ft}$. in height; but it was thought by many that rooms $7 \mathrm{ft} .6 \mathrm{in}$. in height would be quite satisfactory. Others feared that houses with the lower ceilings would be unsatisfactory on grounds of health or of comfort. Prof. Crowden described a survey of some trial houses that were built with rooms only $7 \mathrm{ft} .6 \mathrm{in}$. high. The families who lived in them did so in comfort. Very few expressed the opinion that they would prefer higher rooms, and the majority had not noticed that the ceilings were lower than usual. The conditions specified in the codes of practice were readily main. tained in these houses.

When ordinary gas wash-boilers and cookers were used in small kitchens these became undesirably hot and steamy, and the air was contaminated with products of combustion, unless the ventilation greatly exceeded the 2,000 cu. ft. of fresh air per hour laid down, or unless flues were provided to remove the products of combustion.

Two examples were given of the failure of occupants to make proper use of provisions for ventilating their houses. In one house the excessive use of draught excluding devices made it impossible to use a solidfuel fire, while a gas fire made the air unpleasant, even though the heating was inadequate. In the second example, the deliberate restriction of ventila. tion resulted in four deaths from carbon monoxide poisoning due to the incomplete combustion of coal gas.

In a paper on problems of working conditions in the home, Dr. J. R. Brown described experiments in which women engaged in washing clothes were studied, the work being done without the aid of washing machines. Careful measurements were made of the thermal environment as the work proceeded, the subjective impressions of heat and of moisture of the experimental subjects were noted, their blood 
pressures and pulse-rates were measured and used for computing the Crampton index of vasomotor tone, and the electrical conductivity of the skin was measured. From experiments carried out under control conditions it was concluded that changes in the Crampton index were related to changes in thermal stress. The numerical value of the index declined as the women subjects felt hotter and more fatigued. It has been found that, until the skin becomes visibly wet with sweat, there is a linear relation between its electrical conductivity and the number of active sweat glands.

Dr. A. Parker spoke on house heating and atmospheric pollution. Domestic chimneys are responsible for a million tons of smoke a year and for a million tons of sulphur dioxide, and the solution to the problem lies in the use of smokeless fuels-gas, electricity and coke-in proper balance. Problems of economics as well as fuel technology arise here. Only one day's supply of gas can be stored, and it is impracticable to store electricity on a large scale, so that the main stand-by must necessarily be solid fuel. Coke should not be regarded as a surplus product arising from the manufacture of gas, but rather the needs for coke and for gas should be taken into account together. People should regard coke as a valuable smokeless fuel in its own. right, and not merely as partly-used coal. Dr. Parker thinks the problem is not insoluble. In Britain, he said, people insist on having open fires, and such fires are perhaps desirable in this climate, but there is no prospect of burning bituminous coal in such fires without creating smoke. When convective methods of heating are used, people tend to demand an air temperature about $8^{\circ} \mathrm{F}$. higher than with radiant heating, with consequently greater fuel consumption. It might be suggested that district heating should be extended; but with this form of heating it is usual to make a weekly charge for heat without reference to the quantity used, so that the consumer has no incentive to practise economy, with the result that the amount of fuel used per house with district heating is greater than with open fires.

Mr. J. B. Dick spoke about factor's of design and construction affecting heating and ventilation in dwellings. It is the experience of the Building Research Station that, with an internal flue, about 40 per cent of the heat from an open fire is delivered into the house, and with such a fire an acceptable standard of comfort can be obtained at lower cost than with a hot-water radiator. It is important not to provide a heating system that will be too costly for the householder to maintain.

Recent improvements in construction were doscribed. An 11-in. cavity wall with a foamed-slag inner leaf has an overall thermal transmittance of only two-thirds that of an 11 -in. cavity wall entirely of brick, and a transmittance of less than half that of a solid 9-in. brick wall. The use of glass wool for roof insulation was described. Besides reducing fuel consumption to maintain a given air temperature, good thermal insulation also raises the temperature of the inner surface of external walls and thus enhances comfort. 'Temperature gradients can be caused by the convection from cold walls or windows. Better insulation of the walls and tubular heaters beneath windows can cure this. Floor heating also helps to prevent these gradients, and when heating is by the admission of warmed air this should enter at low level and air exits should be placed at high level.

The temperatures maintained in houses depend not only on the preferences of the occupants, but also on the cost. Thus, in some experimental houses the temperatures in the living-rooms at 9 p.m. commonly averaged $65^{\circ} \mathbf{F}$., but during cold weather the figure fell to $60^{\circ} \mathrm{F}$. It was evident that the householders would not pay for the heat then required to maintain a temperature of $65^{\circ} \mathrm{F}$. With improved insulation some of the potential saving of fuel may not be realized because higher temperatures are likely to be maintained by the occupants. Hence emphasis must be placed on better insulation without increased capital cost. One way in which this can be achicved is by use of the foamed-slag inner leaf in cavity walls.

Dr. C. G. Douglas, who opened the discussion, believes that the problems of heating and ventilating factories and offices are easier than those relating to houses. Instrumental methods have been devised for the study of the indoor environment, and the difficulties that now arise are mainly economic. It is important to consider what could be done to provide comfortable warmth for aged people with limited resources. The high cost of coal has driven many people to use kerosene for supplementary heating.

\section{AHMEDABAD TEXTILE INDUSTRY'S RESEARCH ASSOCIATION}

\section{By DR. VIKRAM A. SARABHAI \\ Director}

$\mathrm{O}^{\mathrm{N}}$ April 10, Mr. Jawaharlal Nehru, Prime Minister of India, opened the new laboratory building at Navrangpura, Ahmedabad 9, of the Ahmedabad Textile Industry's Research Association, the foundation stone of which was laid in November 1950 by the late Sardar Vallabhbhai Patel, Deputy Prime Minister of India. The Association is modelled on the same lines as the research associations in Great Britain, and this constitutes the first enterprise of its kind in which industry and the Government of India have co-operated in the field of research. The past five years have witnessed the growth in India of a chain of national laboratories inspired by Sir Shanti Bhatnagar, director of the Council of Scientific and Industrial Research, and Sir Shanti has also been actively associated with the growth and development of the new Association at Ahmedabad, which is the second largest centre of the textile industry in India.

The idea of establishing a textile research laboratory maintained by the joint effort of industry and the Government of India was first conceived by the Ahmedabad Millowners' Association in 1944, and the Ahmedabad Textile Industry's Research Association was registered in December 1947. Its seventy "one founder-members made an initial contribution of approximately $£ 370,000$ towards the initial expenses, and the Government of India gave approximately $£ 145,000$. The recurring expenses are shared equally by industry and the Government. Recently, membership of the Association was thrown open to mills all over India, and co-operative research is now increasingly made use of by the premier industry of the country.

The laboratorios are on the Gujarat University campus and consist of a multi-story central block, covering an area of 100,000 sq. ft., which accommodates the library, offices and laboratories of the various research divisions, the administrative offices, the stores and precision workshop, and the services in a basement. The block is connected at one end to 